\title{
Millets' Consumption Probability and Demand in India: An Application of Heckman Sample Selection Model
}

\author{
M. Umanath ${ }^{1 *}$, R. Balasubramaniam ${ }^{2}$ and R. Paramasivam ${ }^{1}$ \\ ${ }^{1}$ Madras Institute of Development Studies, Chennai, India \\ ${ }^{2}$ Department of Market Extension, Tamil Nadu Agricultural University, Coimbatore, India \\ *Corresponding author: umanatheconomics@gmail.com
}

\begin{abstract}
This paper aims to analyze the determinants of the choice probability of millet consumption and the demand for major millets at household level in India. For this, we used consumer expenditure survey data collected by the National Sample Survey Organization (NSSO) for the years 2004-05 and 2011-12. Heckman sample selection model was used to estimate the functional relationship between household level characters and millet consumption as zero expenditure is encountered for many of the households in the data set. The analysis revealed that the prices of millets and other food commodities had statistically significant effect on both millet consumption probability and the quantity demanded of millets while per capita income was not an important determinant. It is confirmed that the millets continue to be treated as inferior goods in India. Besides, age of household head has a positive relationship with the millet consumption, whereas larger household size and higher educational level decreased the probability of millet consumption and quantity demanded.
\end{abstract}

Keywords: Millets, prices, income, Heckman, maximum likelihood, households, food

Millets are considered as ideal food to human beings because of their high nutritive values. Millets contain high level of proteins, minerals, vitamins, antioxidants, and they are non-glutinous and non-acid forming diets compared to other cereals and therefore called as 'nutritious millets' or 'nutricereals'. Specifically, pearl millet and finger millets provide protein at the rate of 11.8 and 7.4 g per 100 gram grain, respectively, and the fat content is low in these millets (around $1.3 \mathrm{~g}$ per $100 \mathrm{~g}$ grain) (Sakamoto, 1982; Muthamilarasan et al. 2015). Besides, millets have higher levels of low Glycemic Index (GI) non-starch polysaccharides and dietary fibers which protects against diabetes. The important millets cultivated and consumed in India include sorghum, pearl millet, finger millet (ragi), foxtail millet (kangni), kodo millet (kodo), proso millet (cheena), barnyard millet (sawan) and little millet (kutki) (NAAS, 2013). These millet crops are mainly grown in the semi-arid regions of Asia and Africa, accounting for an area of 32.12
$\mathrm{M}$ ha (million hectare) and production of $28.76 \mathrm{M}$ $\mathrm{t}$ (million tonnes) in 2013. Most millet crops have shorter life cycle of 60-90 days, and are able to withstand the situation of minimal moisture, high temperature and soil with poor nutrients (Lata et al. 2013; Bergamini et al. 2013). The salient features contributing for wider adoption of these crops in the cropping systems of semi-arid regions include climate resilience, low labour and market input requirement, resistance to pests and diseases and their capability to sequester carbon and reduce the burden of greenhouse gas thereby supporting low carbon agriculture. Despite the easy availability of nutritionally rich food through millet consumption, India still faces malnutrition problems. National Family Health Survey found that about 46 percent of the children under five years of age are moderate to severely underweight (thin for age), 38 percent are moderate to severely stunted (short for age), and nearly 19 percent are moderate to severely futile (thin for height) (Kanjilal et al. 2010; Rajaram et al. 
2007), which have resulted in poorest performance of India in Human Development Index with $123^{\text {rd }}$ rank out of 162 countries in 2015. India's expenditure on the prevention of micronutrient malnutrition was about 0.8 to 2.4 percent of the GDP. The annual per capita intake of sorghum at the national level decreased drastically from $8.5 \mathrm{~kg}$ to $1.58 \mathrm{~kg}$ in urban areas and by $19.2 \mathrm{~kg}$ to $2.424 \mathrm{~kg}$ in rural areas between 1972-73 and 2011-12; while pearl millet intake also declined rapidly from 11.5 $\mathrm{kg}$ to $0.97 \mathrm{~kg}$ in rural areas and from $4 \mathrm{~kg}$ to 2.82 $\mathrm{kg}$ in urban areas (Rao et al. 2009; Basavaraj et al. 2010; NSSO, 2012).

The reason for the decline of millet intake is overdependency on rice and wheat, which may provide over 50 percent of the average Indian household's caloric intake. In recent times, notable changes in the dietary pattern of households across the state have been observed from cereals to high value food commodities such as livestock products, fruits, vegetables and beverages (Kumar et al. 2011; Chatterjee et al. 2006; Bansil, 1999; Radhakrishna, 2005); increase in per capita income, growing urbanisation, and changing tastes and preferences (Chand, 2007) and less attention by researchers on these so-called neglected and underutilized species (Padulosi and Hoeschle-Zeledon, 2004) affects neglected nutrition and health opportunities (Smith, 1982; Frison et al. 2006; Hawtin, 2007; Smith and Longvah, 2009). Markets for millet grains is imperfect and shallow in nature particularly during surplus production. In turn, millet producers received lower prices as compared to the millets purchased for consumption at the retail level (Nagarajan et al. 2005). Processing of millets for consumption at household level is tedious and often time consuming while the tastes and preferences of younger generations are shifting away from millets. All these factors have contributed for millets being treated as inferior food with low to negative income elasticity of demand and positive price elasticity. Along with other factors such as easy access to irrigation and markets for high-value crops, the millet crops have been slowly and steadily replaced by high-value crops in their traditional production areas (Chandrakanth and Akarsha, 2011).

Several studies have reported that such a transition in food consumption pattern is influenced by increasing growth in income and employment, availability of expected fresh and processed food products in the market, improvements in transportation and storage facilities and rise of supermarkets (Kumar et al. 2011; Vasileska and Rechkoska, 2012; Chengappa et al. 2007). Besides these macro drivers, a few specific household-level characteristics also influence the purchasing and consumption of different food products. These characteristics include prices of foods, disposable income of households, age, education level and gender of household head, asset position, household size, location of the dwelling, heterogeneous culture of different ethnic groups, changing lifestyles and increasing health consciousness (Quah and Tan, 2009; Pazarlioglu et al. 2007). In the case of millet, there is limited literature on economic / econometric analysis of millet consumption pattern and its determinants (Green and Park, 1998; Jones and Akbay, 2000; Hsu and Kao, 2001; Schmit et al. 2002; Hatirli et al. 2004; Pazarlioglu et al. 2007).

Although the human consumption demand is likely to play a major role in the development of millets, detailed information on the nature of demand and preferences of consumers regarding millet products is unavailable. Such information is needed for producers and market actors to take market-oriented production decisions to benefit from growing markets (Lapar et al. 2010). Given their essentiality in households' diet, it is crucial for policy makers and other stakeholders involved in production, marketing and processing of millets to understand the factors determining the consumption of these products. Most of the studies in India have largely focused on the magnitude of changes in the consumption pattern of food commodities, but none of these studies focused on the factors affecting the food consumption transition at household level (Kumar et al. 2007). Only a few studies have comprehensively looked into the impact of price and per capita income by estimating demand elasticities in India (Kumar et al. 2014; Kumar et al. 2011; Mittal, 2007; Mittal, 2010). This highlights the fact that the influence of household level characteristics on consumption of millet products is insufficiently understood in India. Therefore, this paper focusses on filling this gap in knowledge by analyzing their relationship which is crucial for policy formulation. This study is a modest attempt in this regard that draws attention to the determinants of preference 
and the amount of consumption of millet in the Indian context.

\section{DATA BASE AND METHODOLOGY}

\section{Data}

The household data on dietary pattern and consumer expenditures collected by the National Sample Survey Organization (NSSO), Government of India at national level, pertaining to the periods 2004-05 and 2011-12, were used for this study to capture the temporal and spatial variation in the prices of the commodities, income, and taste and preferences of the consumers. These comprehensive National Sample Survey (NSS) data with a sample size of over 100,000 households covering both rural and urban areas has a high acceptance in research and policy. The detailed sampling procedure has been given in the reports on Household Consumption of Various Goods and Services in India for 2004-05 and 2011-12, released by the Planning Commission, Government of India.

\section{Methodology}

It is a common problem in the expenditure survey data on food commodities that large number of respondents may report non-participation or zero consumption of some of the food commodities due to taste and preference on specific food, and socioeconomic and cultural limits confronted by the respondents (Cheah and Tan, 2014). In case of such a censored data, the use of ordinary least squares regression analysis yields biased, inconsistent and inefficient regression parameters since limiting the range of the dependent variable leads to a non-zero mean of the error term (Greene, 2007). Though the single equation censored Tobit (Tobin, 1958) model is used to deal with such censored data, it should be stressed that the model is unduly restrictive as it implicitly assumes that the independent variables have the same impact on the probability of preference and the consumption of food commodities. In our study, Heckman sample selection model is employed to accommodate such a kind of zero consumption or non-participation problem encountered in consumer expenditure survey data on millets. Following the notations from Yen and Rosinski (2008), the Heckman sample selection model can be written as follows:

$$
\begin{aligned}
\log & =\quad{ }^{\prime} \beta+ & & ' \alpha+>0, \\
y & =0 & \text { if } & z^{\prime} \alpha+u \leq 0,
\end{aligned}
$$

where, $y$ denotes the dependent variable of the model; $x$ and $z$ represent the vectors of independent variables which explain the dependent variable; $\beta$ and $\alpha$ denote conformable vectors of parameters; $u$ and $v$ are the error terms which are distributed as bi-variate normal with zero means and a finite covariance matrix:

$$
\left[\begin{array}{l}
u \\
v
\end{array}\right] \sim N\left\{\begin{array}{l}
0 \\
0
\end{array}\right\},\left[\begin{array}{ll}
1 & \sigma \rho \\
\sigma \rho & \sigma^{2}
\end{array}\right]
$$

where, $\sigma$ denotes the standard deviation of $v$, and the correlation between $u$ and $v$ is represented by $\rho$. The standard deviation of $u$ is not known, thus it is set at unity, given that the selection outcomes are observed as binary, which means that the value is either 1 or 0 . The sample likelihood function is:

$$
\begin{aligned}
& L \prod_{y=0}\left[1-\Phi\left(z^{\prime} \alpha\right)\right] \prod_{y>0} \Phi\left[\frac{z^{\prime} \alpha+\rho\left(\log y-x^{\prime} \beta / \sigma\right)}{\left(1-\rho^{2}\right)^{1 / 2}}\right] \\
& y^{-1} \frac{1}{\sigma} \phi\left(\frac{\log -x^{\prime} \beta}{\sigma}\right)
\end{aligned}
$$

where, $y^{-1}$ is the Jacobian transformation from $\log$ $y$ to $y$, and $\phi($.$) and \Phi($.$) are the standard normal$ probability density function (pdf) and cumulative distribution function (cdf), respectively. When the errors are independent $(\rho=0),(3)$ reduces to that of a two-part model, in the case where the loglikelihood function is separable in parameters $\alpha$ and $[\beta, \rho]$, and therefore estimation can be broken down to a probit model (to estimate $\alpha$ ) using the whole sample and a linear regression of $\log y$ on $x$ (to estimate $\beta$, and $\rho$ ) using only the on-limit observations.

There is continued interest in the marginal effect calculation in the sample selection model. Based on the procedure given by Yen and Rosinski (2008), the conditional mean of the dependent variable $y$ is:

$$
\begin{gathered}
E(y \dddot{y}>)=\left(x^{\prime} \beta+\sigma^{2}\right) \\
\Phi\left(z^{\prime} \alpha+\sigma \rho\right) / \Phi\left(z^{\prime} \alpha\right)
\end{gathered}
$$

Since the marginal probability of a positive observation is: 


$$
\operatorname{Pr}(y>0)=\Phi\left(z^{\prime} \alpha\right)
$$

the unconditional mean of $\mathrm{y}$ is:

$$
E(y)=\exp \left(x^{\prime} \beta+\sigma^{2} / 2\right) \Phi\left(z^{\prime} \alpha+\sigma \rho\right)
$$

Differentiating Equations (4), (5) and (6) gives the marginal effects on probability, conditional mean and unconditional mean of a common element of $x$ and $z\left(\right.$ say $\left.x_{j}=z_{j}\right)$ :

$$
\begin{aligned}
& \partial \operatorname{Pr}(y>0) / \partial x_{j}=\phi\left(z^{\prime} \alpha\right) \alpha_{j} \\
& \partial E(y \mid y>0) / \partial x_{j}=\left[\Phi\left(z^{\prime} \alpha\right)\right]^{-2} \\
& \quad \exp \left(x^{\prime} \Re \Re^{\prime} / 2\right)\left\{\left[\Phi\left(z^{\prime}\right)\left(z^{\prime}+\quad\right)\right.\right. \\
& \left.\left.\quad-\phi\left(z^{\prime} \alpha\right) \Phi\left(z^{\prime} \alpha+\sigma \rho\right)\right] \alpha_{j}+\Phi\left(z^{\prime} \alpha+\sigma \rho\right) \beta_{j}\right\} \\
& \partial E(y) / \partial x_{j}=\exp \left(x^{\prime} \beta+\sigma^{2} / 2\right) \\
& \quad\left[\phi\left(z^{\prime} \alpha+\sigma \rho\right) \alpha_{j}+\Phi\left(z^{\prime} \alpha+\sigma \rho\right) \beta_{j}\right]
\end{aligned}
$$

These marginal effects can be evaluated at data points of interest, such as the sample means of explanatory variables.

\section{Variables Selection}

Heckman sample selection (ML) model was estimated for each millet consumption individually. Quantity consumed of these millets (in $\mathrm{kg}$ ) was taken as the dependent variable rather than expenditure. Based on the equation (1), the dependent variable refers to the natural logarithm of the quantity of millets consumed by a household in a year. Independent variables are as follows: prices $^{1}$ of millets and other food groups (in rupees), monthly per capita income ${ }^{2}$ (in rupees), household size (in numbers), age of household head (in years), and

\footnotetext{
IPrice response was obtained on the basis of unit values. Unit price for different food groups was derived by dividing the value of these food items by total quantity consumed by a particular respondent in a region. Price for these food items which is not consumed by any respondent in a region was given the average price of the corresponding region. The use of the unit value as a price for a food item have been thoroughly applied by Deaton (1990; 1997), Crawford et al. (2003) and Kedir (2005). The prices of the food items were deflated with consumer prices index (CPI) of respective years to convert them into real term.

${ }^{2}$ We used total monthly per capita expenditure on food and non-food commodities as a proxy for per capita income.
}

dummy variables for education level ${ }^{3}$, gender of household head (1 for woman headed households and 0 for man headed households), presence of dwelling units ( 1 for owning dwelling units and 0 for non-owning), presence of regular salary earners ( 1 for having regular salary earners and 0 for not having), intercept dummy for own production of millets ( 1 for own production of millets and 0 for others), for possibility of having food away from home (FAFH) (1 for FAFH and 0 for others), for time period ( 1 for the households in 2011-12 and 0 for households in 2004-05) and for economic classes $^{4}$. Choosing independent variables is one of the important empirical issues in the estimation of Heckman regression model. As in the other sample selection model, we used exclusion conditions to identify the model parameters. Although there is no a priory exclusion conditions for the current samples, we excluded the age variable in the consumption equation which was used in the selection equation. Use of such different sets of variables in the two equations ensures that the model is identified. Stata version 13.0 was used to estimate the log likelihood function of the Heckman sample selection model.

\section{RESULTS AND DISCUSSION}

\section{Profile of Socio-economic Characters and Millet Consumption of Sample Households}

Descriptive statistics of millet consumption profile and related variables pertaining to sample households are presented in Table 1. It is observed that, sorghum occupied larger proportion of total millet consumption in terms of both quantity and value. Pearl millet was the second predominantly consumed millet in India. It is assumed that millets are treated as inferior commodities and their consumption would decrease as income increases. During 2004-05, average annual per capita income

${ }^{3}$ Education levels- illiterates, non-institutional education, primary education, high schooling, higher secondary and collegiate and above.

${ }^{4}$ We used state wise poverty line to classify the entire sample size as poor, middle and high income class. For this, poverty estimates, released by the Planning Commission, Government of India for 2004-05 and 2011-12 were used for each individual states. Accordingly the 'poor' income class comprised of households who have income level below the poverty line (BPL), between $B P L$ and 150 per cent of BPL were grouped as 'middle income' and households having per capita income above 150 per cent of BPL were categorized as 'higher income' group. 
Table 1: Descriptive statistics of millet consumption and related variables

\begin{tabular}{|c|c|c|c|c|}
\hline \multirow[t]{2}{*}{ Variables } & \multicolumn{2}{|c|}{ 2004-05 } & \multicolumn{2}{|c|}{ 2011-12 } \\
\hline & Rural & Urban & Rural & Urban \\
\hline Annual finger millet consumption $(\mathrm{Kg})$ & 1.57 & 0.92 & 0.91 & 0.73 \\
\hline Annual finger millet finger millet expenditure $(₹)$ & 18.9 & 11.69 & 11.18 & 10.52 \\
\hline Annual sorghum consumption $(\mathrm{Kg})$ & 5.16 & 2.70 & 2.43 & 1.59 \\
\hline Annual sorghum expenditure (₹) & 70.54 & 41.36 & 53.54 & 41.34 \\
\hline Annual pear millet consumption $(\mathrm{Kg})$ & 4.67 & 1.36 & 2.82 & 0.97 \\
\hline Annual pearl millet expenditure $(₹)$ & 54.83 & 16.79 & 30.75 & 13.48 \\
\hline Annual maize consumption $(\mathrm{Kg})$ & 3.69 & 0.31 & 1.57 & 0.17 \\
\hline Annual maize expenditure $(₹)$ & 38.68 & 3.88 & 18.21 & 3.06 \\
\hline Annual other millets consumption $(\mathrm{Kg})$ & 0.11 & 0.02 & 0.07 & 0.02 \\
\hline Annual other millets expenditure (₹) & 1.28 & 0.34 & 1.30 & 0.64 \\
\hline Annual total millet consumption $(\mathrm{Kg})$ & 15.25 & 5.30 & 7.80 & 3.47 \\
\hline Annual total expenditure on millets $(₹)$ & 185.07 & 74.15 & 115.22 & 69.18 \\
\hline Annual per capita income $(₹)$ & 6705.6 & 12628.2 & 17159.64 & 31555.8 \\
\hline Age in years & 46.06 & 46.15 & 46.93 & 46.46 \\
\hline Household size & 6.10 & 5.60 & 5.63 & 5.20 \\
\hline \multicolumn{5}{|l|}{ Education (in percent) } \\
\hline Illiterate & 36.96 & 19.71 & 29.08 & 15.41 \\
\hline Non-intuitional education & 1.55 & 0.89 & 0.68 & 0.45 \\
\hline Primary & 24.56 & 20.55 & 25.48 & 18.05 \\
\hline High school & 25.89 & 32.36 & 29.39 & 31.65 \\
\hline Higher secondary & 5.06 & 8.73 & 7.09 & 11.8 \\
\hline Collegiate & 5.97 & 17.76 & 8.28 & 22.64 \\
\hline Presence of dwelling unit (in percent) & 14.21 & 8.39 & 94.6 & 67.27 \\
\hline Male headed households (in percent) & 89.26 & 87.89 & 89.31 & 87.41 \\
\hline Presence regular salary earners (in percent) & 2.95 & 4.9 & 21.53 & 43.07 \\
\hline Food away from home (in percent) & 6.53 & 11.69 & 7.35 & 12.24 \\
\hline Own production of sorghum (in percent) & 2.52 & 0.36 & 1.75 & 0.28 \\
\hline Own production of finger millet (in percent) & 1.48 & 0.06 & 1.07 & 0.1 \\
\hline Own production of pearl millet (in percent) & 2.04 & 0.15 & 1.78 & 0.14 \\
\hline Own production of maize (in percent) & 5.15 & 0.24 & 4.06 & 0.19 \\
\hline
\end{tabular}

Source: consumer expenditure survey on food and non-food commodities in 2004-05 and 2011-12.

was ₹ 6705 for rural households and ₹ 12628.2 urban households, whereas the corresponding figures for the year 2011-12 were ₹ 17159.64 and ₹ 31555.8. Real income has increased in both rural and urban areas, but the per capita income of the rural people about 50 percent lesser than the urban household income. On an average, during 2004-05, Indian rural households consumed 5.16, 4.67, 3.69 and $1.57 \mathrm{~kg}$ per year of sorghum, pearl millet, maize and finger millet, respectively. Whereas urban households consumed 2.7, 1.36, 0.31 and $0.92 \mathrm{~kg}$ of the same millets during the same period. A comparison of millet consumption during 2004-05 and 2011-12 revealed that there was a declining trend in the millet consumption pattern over the period. Millet consumption has decreased by nearly 50 percent in rural areas and 35 percent in urban areas during the year 2011-12 over the year 2004-05. Further, rural households are considered as the largest consumer than urban households, and the difference between rural and urban households in total millet consumption was nearly $10 \mathrm{~kg}$ in 2004-05 and $4 \mathrm{~kg}$ in 2011-12. Hence, higher income and urbanization have led to reduced consumption of millets.

The average year of age of household head was 46 in both rural and urban regions. Education level is 
classified into six groups. Around 37 percent of the head of the households in rural areas were illiterate in 2004-05 whereas only around 18 percent of the household heads were illiterate in urban regions in the same period. In the country, primary and high school level education together, shared more than 50 percent in all the periods. Household head having higher secondary and collegiate level education was more in urban regions than rural region. It is a worthy to notice that there was declining trend in the share of illiterate considerably in both the regions. More than 85 percent of household head were male and they are the main decision maker in the household. Households having regular salary earners were more in urban region in both period and it increased tremendously in both regions in 2011-12. Nowadays, having food away from home is a common practice followed by Indian households.

Households owning dwelling units were more in rural regions than urban regions and more in 2011-12 over 2004-05. Also, the share of households having food away from home in both regions increased remarkably in 2011-12. It was practiced by 6.53 percent households in rural regions in 200405 whereas it was 11.69 percent in urban regions during the same period. Households producing the millets in their own farm were more in rural regions than the urban region and the trend decreased in 2011-12. Own production of millet in the farms ensures more quantity consumption.

\section{Estimation results of Heckman Sample Selection Model}

In this section, we discuss the results of the estimated functional relationship between the quantity consumed of different millets and the independent variables which affect consumption behavior of millets at the household level. For this, we employed Heckman sample selection model because the data set used for the analysis consisted of zero expenditure for many households. The results of ML estimation for pearl millet and maize show that the estimated error correlation coefficient $(\rho)$ between selection and consumption equations and its corresponding covariance term $(\lambda)$ are significant. Besides, Likelihood Ratio (LR) test rejected independence of the error terms of the selection and consumption equations. But, in the case of finger millet and sorghum, LR test did not reject independence of the error terms of the selection and consumption equations. All these suggest the importance of selectivity correction in the present analysis of pearl millet and maize consumption. Most of the estimated coefficients in both the selection and consumption equations of these millets were statistically significant (Appendix I).

With the separate equations to accommodate sample selection and level, and with the logarithmic transformation in the dependent variable, the effects of explanatory variables on the probability and the level of consumption are non-trivial. Further, as discussed in the methodology section, marginal effects on probability, conditional and unconditional levels (Equations 7, 8 and 9) were worked out to explore the impacts of household characters on the probability of preference and the quantity of millet consumption. The effects on the conditional level explain what makes those consuming millets consume either more or less i.e., the conditional marginal effects measure how the consumption of millets changes due to a specific independent variable for current millet consumers. The effects on probability explain the binary decision on consumption, viz., to consume or not to consume, i.e., the marginal effects of probability measure how those consumers who are at zero consumption start consuming millets due to the influence of independent variables. The effects of unconditional level provide an overall assessment of what contributes to a consumption level by increasing (or decreasing) either the probability or conditional level.

\section{Impact of Changes in the Own Price of Different Millets on Household Consumption}

To assess the impact of independent variables on the given millets consumption, marginal effect was calculated using the maximum likelihood results obtained from the Heckman sample selection model. The respective estimated marginal effects on probability, conditional and unconditional levels for finger millet, sorghum, pearl millet and maize are presented in Table 2. Except sorghum, own price of all the millets significantly affects the consumption probability of these millets. For instance, an increase in the price of finger millet by ₹ 10 per $\mathrm{kg}$ reduces the consumption probability by 
Table 2: Determinants (Marginal effect) of consumption probability and demand for finger millet, sorghum, pearl millet and maize

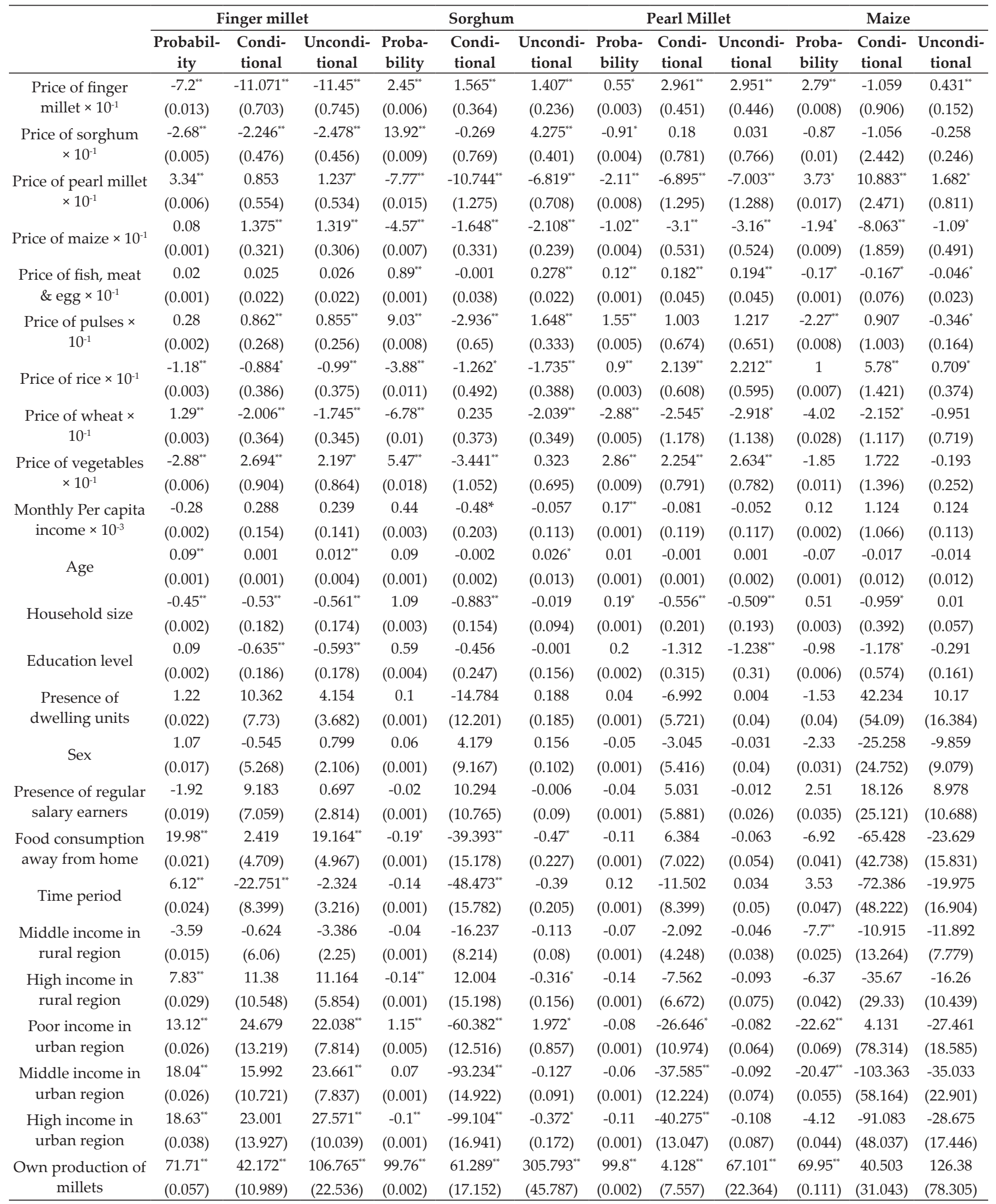

Note: Figures in parentheses indicate standard errors; Double asterisk $\left.{ }^{* *}\right)$ indicates significant at one percent level and single asterisk $\left({ }^{*}\right)$ indicates significant at five percent level. 
7.2 percent. Similarly, the consumption probability of pearl millet and maize was reduced by 2.11 and 1.94 percent, respectively, when own prices of these millets increase by ₹ 10 per $\mathrm{kg}$.

Conditional (current consumers) and unconditional (average consumers) level consumption of finger millet, pearl millet and maize were inversely related to increased prices of their own. For example, the conditional and unconditional annual consumption of finger millet in India are expected to reduce by $11.07 \mathrm{~kg}$ and $11.45 \mathrm{~kg}$, respectively, when ₹ 10 increases in the own price of the finger millet. Similarly, the quantity consumed of pearl millet and maize decreased by $6.89 \mathrm{~kg}$ and 8.06 $\mathrm{kg}$ at conditional level and $7.00 \mathrm{~kg}$ and $1.09 \mathrm{~kg}$ at unconditional level, respectively, as the own prices of pearl millet and maize increase by ₹ 10 (Table 2).

\section{Impact of Changing Cross Prices and Income on Millet Consumption}

An increase in the price of finger millet leads to higher consumption probability and demand for all other millets. Similarly, increased price of pearl millet causes increased consumption of finger millet and maize and increased price of maize influences the consumption of finger millet positively. It revealed that there was a substitution relationship between finger millet and pearl millet; and between finger millet and maize.

The increased price of fish, meat and egg increased the probability of consuming pearl millet and decreased the maize consumption. The increased price of rice was less likely to consume and demand finger millet and sorghum. Probability and consumption demand for all millets was less when the price of wheat increases further.

There was no significant impact of increased income on the millet consumption. All coefficients are nonsignificant except current consumption of sorghum and the probability of more consumption of pearl millet. The less impact of income on the millet consumption and complementary nature with rice and wheat may be due to smaller budget share of millets to total expenditure. This indicates that all millets are treated as inferior goods and there was a changing food habits and taste within the food system not including millets (Table 2).

\section{Impact of Changes in Household Level Characters on Millet Consumption}

As age of household head increases, the consumption probability and demand for finger millet and sorghum increased. Household size was inversely related to the consumption of finger millet, sorghum and pearl millet. Education level was also inversely related to the consumption of finger millet, pearl millet and maize. Habit of eating food away from home increases the choice probability and demand for finger millet whereas it reduced the choice probability of demand for sorghum. When compared to the year 2004-05, there was a more probability to consume finger millet in 2011-12 but quantity consumed has decreased over the years. When compared to the poor people in rural regions, high income groups in rural areas and all income groups in urban areas were more likely to consume finger millet. Also, quantity demand of finger millet was more among these income groups. In the case of sorghum and pearl millet, only urban income groups show significant relationship between income and quantity consumed but the relationship was negative. All these indicate that sorghum and pearl millet were not preferred by urban consumers, while they were favourable towards consuming finger millet. This is possibly because of the fact that finger millet is available in the form of flour for long time while availability of flour form of sorghum and pearl is limited. All the millets have higher probability and quantity consumption when they are produced in the own farm of households.

\section{CONCLUSION}

More emphasis is being placed on production and consumption of millets in recent times for many reasons. As climate change is going to impact food security through reduced yield of rice due to increase in temperature and increased frequency of flood / drought, future food security has to lean on millets which are more resilient to bio-physical stresses. Further, the nutritional benefits of millets has brought millets to the centre stage as a major contributor to the nutritional security of the households. This study has made an attempt to understand the factors affecting the demand for millets in rural and urban areas. The own price effects for all millets were negative indicating that the households are less likely to 
consume when own prices of these millet increases. Analysis of cross price effects indicates that increase in the price of finger millet leads to higher consumption probability and demand for all other millets. Similarly, increased price of pearl millet causes increased consumption of finger millet and maize and increased price of maize influences the consumption of finger millet positively. Though most of the household categories preferred to consume finger millet over the other millets, finger millet was found to be substituted by pearl millet and maize, in the event of rise in finger millet prices. Income was not the main factor determining the amount of millet consumption, probably because millets are the traditional staples for low income households, while high income groups have also started consuming millets in recent times due to the health concerns arising out of consuming major millets. Region-wise preference of millets indicates that finger millet is preferred by the urban people while other millets are less likely to be consumed in urban as compared to the rural poor. Among the household characteristics, age of the household head has a positive relationship with millet consumption. This might be due to the importance given for the traditional food values by the old aged people. Contrastingly, higher education level has a negative relationship with the consumption of millets. This could be because of consumption of high value commodities like polished rice or wheat, acts as a societal prestige at one end when compared to the consumption of so-called inferior good like millets.

In order to increase the consumption of millets, awareness should be created explicitly among the children and youth about the superior level of millets in nutritional chart. Besides, like the major cereals such as rice and wheat, millets could be supplied in the Public Distribution System (PDS). Since the study results showed the inverse relationship between consumption of millets and its own price, supplying millets in PDS at a fair price would boost both the production and consumption of millets. Value addition and modernization of the processing sector of millets may benefit the urban and high-income households to consume more quantity of millets or millets-based food products. Improvement and dissemination of post-harvest processing technologies related to millets in rural areas may create employment and agribusiness opportunities.

\section{REFERENCES}

Basavaraj, G., Parthasarathy Rao, P., Bhagavatula, S. and Ahmed, W. 2010. Availability and Utilisation of Pearl Millet in India. Journal of SAT Agricultural Research, 8: 1-6.

Bergamini, N.P.S., Bala, R.S. and Yenagi, Nirmala. 2013. Minor millets in India: a neglected crop goes mainstream. In: Diversifying Food and Diets: Using Agricultural Biodiversity to Improve Nutrition and Health, Biodiversity, Eds. D. Fanzo., T. Hunter., F. Borelli. and Mattei, Journal of International, Rome, 313-325.

Chand, R. 2007. Demand for Food grains. Economic E Political Weekly, 42(52): 10-13.

Chandrakanth, M.G. and Akarsha, B.M. 2011. Green Development for Sustainable Agriculture. FKCCI Journal, Karnataka.

Chatterjee, S., Rae, A. and Ray, R. 2006. Food consumption, trade reforms and trade patterns in contemporary India: How do Australia and NZ fit in?. In: Conference Paper, Massy University, New Zealand: Department of Applied and International Economics.

Cheah, Y.K. and Tan, A.K. 2014. Determinants of leisure-time physical activity: Evidence from Malaysia. The Singapore Economic Review, 59(02): 1450017.

Chengappa, P.G., Achoth, L., Mukherjee, A., Reddy, B.R., Ravi, P.C. and Dega, V. 2007. Evolution of food retail chains in India. Agricultural Diversification and Smallholders in South Asia, New Delhi, Academic Foundation.

Crawford, I., Laisney, F. and Preston, I. 2003. Estimation of household demand systems with theoretically compatible Engel curves and unit value specifications, Journal of Econometrics, 114(2): 221-241.

Deaton, A. 1990. Price elasticities from survey data: extensions and Indonesian results, Journal of Econometrics, 44(3): 281-309.

Deaton, A. 1997. The analysis of household surveys: a microeconometric approach to development policy. World Bank Publications.

Frison, E.A., Smith, I.F., Johns, T., Cherfas, J. and Eyzaguirre, P.B. 2006. Agricultural biodiversity, nutrition and health: Making a difference to hunger and nutrition in the developing world. Food and Nutrition Bulletin, 27: 167-179.

Green, G.M. and Park, J.L. 1998. Retail demand for whole vs. low-fat milk: new perspectives on loss leader pricing. In: Annual Meeting of the American Agricultural Economics Association held at Salt Lake City, UT.

Greene, W. 2007. Econometric analysis. Prentice Hall, New York.

Hatirli, S.A., Ozkan, B., Aktas, A.R. 2004. Factors affecting fluid milk purchasing sources in Turkey. Food Quality and Preference, 15(6): 509-515.

Hawtin, G. 2007. Underutilized plant species research and development activities - review of issues and options, GFU/ICUC. International Plant Genetic Resources Institute, Rome, Italy. 
Hsu J.L. and Kao, J.S. 2001. Factors affecting consumers' fluid milk purchasing patterns in Taiwan: product comparisons and marketing implications. Journal of Food Products Marketing, 7(3): 41-51.

Jones, E. and Akbay, C. 2000. An analysis of consumers' purchasing behavior for high-and low-fat milk: A focus on healthy drinking. Journal of Food Distribution Research, 31(1): 124-131.

Kanjilal, B., Mazumdar, P.G., Mukherjee, M. and Rahman, M.H. 2010. Nutritional status of children in India: household socio-economic condition as the contextual determinant. International Journal for Equity in Health, 9-19.

Kedir, A.M. 2005. Estimation of own-and cross-price elasticities using unit values: econometric issues and evidence from urban Ethiopia. Journal of African Economies, 14(1): $1-20$

Kumar, Praduman, Mruthyunjaya and Dey, Madan M. 2007. Long-term changes in food basket and nutrition in India. Economic and Political Weekly, 3567-3572.

Kumar, A., Joshi, P.K., Kumar, P. and Parappurathu, S. 2014. Trends in the consumption of milk and milk products in India: implications for self-sufficiency in milk production, Food Security, 6(5): 719-726.

Kumar, P., Kumar, A., Parappurathu, S. and Raju, S.S. 2011. Estimation of demand elasticity for food commodities in India. Agricultural Economics Research Review, 24(1): 1-14.

Lapar, M.L.A., Choubey, M., Patwari, P., Kumar, A., Baltenweck, I., Jabbar, M.A. and Staal, S. 2010. Consumer preferences for attributes of raw and powdered milk in Assam, Northeast India. ILRI, pp. 103.

Lata, C., Gupta, S. and Prasad, M. 2013. Foxtail millet: a model crop for genetic and genomic studies in bioenergy grasses. Critical Review in Biotechnology, 33: 328-343.

Mittal, S. 2007. What affects changes in cereal consumption?, Economic and Political Weekly, 42(5): 444-447.

Mittal, S. 2010. Application of the QUAIDS model to the food sector in India. Journal of Quantitative Economics, 8(1): 42-54.

Muthamilarasan, M., Dhaka, A., Yadav, R. and Prasad, M. 2015. Exploration of millet models for developing nutrient rich Graminaceous crops, Plant Science. http://dx.doi. org/10.1016/j.plantsci.2015.08.023.

NAAS, 2013. Role of Millets in Nutritional Security of India. Policy Paper No. 66, National Academy of Agricultural Sciences, New Delhi: 16p.

Nagarajan, Latha., Smale, Melinda. and Glewwe, Paul. 2005. Comparing farm and village-level determinants of millet diversity in marginal environments of India: the context of seed systems. International Food Policy Research Institute, Discussion paper 139.

Padulosi, S. and Hoeschle-Zeledon, I. 2004. Underutilized plant species: what are they?, LEISA, 20(1): 56.

Pazarlioglu, M.V., Miran, B., Üçdoğruk, S. and Abay, C. 2007. Using econometric modelling to predict demand for fluid and farm milk: A case study from Turkey. Food Quality and Preference, 18(2): 416-424.

Quah, S.H. and Tan, A.K. 2009. A Heckman sample selection approach to the demand for organic food products: An exploratory study using Penang data. Journal of Food Products Marketing, 15(4): 406-419.

Radhakrishna, R. 2005. Food and nutrition security of the poor: emerging perspectives and policy issues. Economic and Political Weekly, 40(18): 1817-21.

Rajaram, S., Zottarelli, L.K. and Sunil, T.S. 2007. Individual, household, programme and community effects on childhood malnutrition in rural India. Maternal $\mathcal{E}$ Child Nutrition, 3(2): 129-140.

Rao, P.P., Basavaraj, G., Bhagavatula, S. and Ahmed, W. 2009. An Analysis of Availability and Utilisation of Sorghum Grain in India, Journal of SAT Agricultural Research 8.

Sakamoto, S. 1982. Waxy endosperm and perisperm of cereals and grain Amaranth and their geographical distribution. Journal of the Japanese Society of Starch Science, 29: 41-59.

Schmit, T.M., Dong, D., Chung, C., Kaiser, H.M. and Gould, B.W. 2002. Identifying the effects of generic advertising on the household demand for fluid milk and cheese: a two-step panel data approach. Journal of Agricultural and Resource Economics, 27(1): 165-186.

Smith, I.F. 1982. Leafy vegetables as source of minerals in southern Nigerian diets. Nutrition Report International, 26:679-688.

Smith, I.F. and Longvah, T. 2009. Mainstreaming the use of nutrient-rich underutilized plant food resources in diets can positively impact on family food and nutrition security - data from Northeast India and West Africa. Acta Horticulturae, 806:375-384.

Tobin, J. 1958. Estimation of relationships for limited dependent variables. Econometrica: Journal of the Econometric Society, 26(1): 24-36.

Vasileska, A. and Rechkoska, G. 2012. Global and regional food consumption patterns and trends. Procedia-Social and Behavioral Sciences, 44: 363-369.

Yen, S.T. and Rosinski, J. 2008. On the marginal effects of variables in the log-transformed sample selection models. Economics Letters, 100(1): 4-8. 


\section{Appendix I}

Estimated Heckman Sample Selection (Maximum Likelihood) model

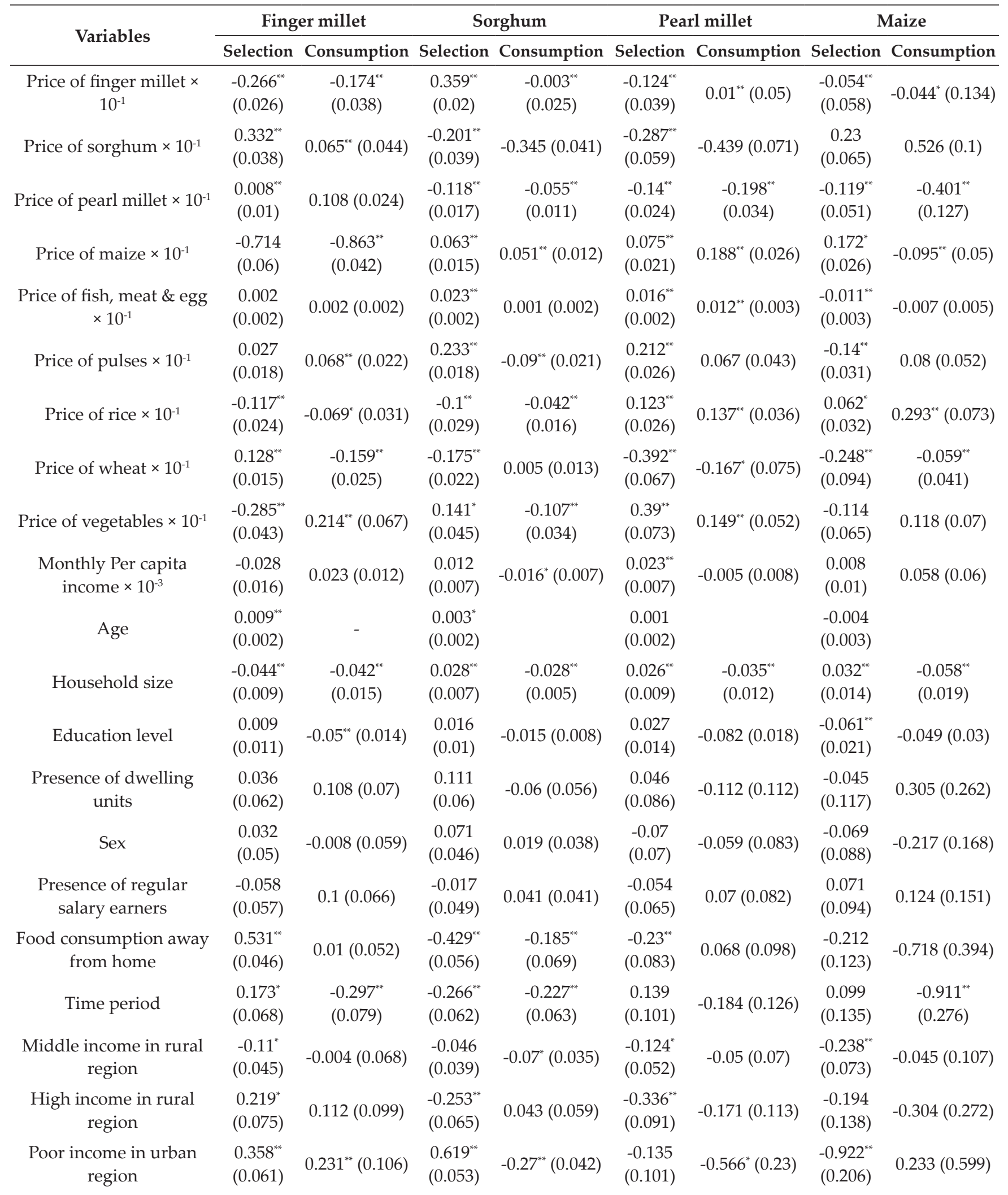




\begin{tabular}{|c|c|c|c|c|c|c|c|c|}
\hline $\begin{array}{l}\text { Middle income in urban } \\
\text { region }\end{array}$ & $\begin{array}{l}0.483^{* *} \\
(0.057)\end{array}$ & $0.148(0.092)$ & $\begin{array}{c}0.077 \\
(0.054)\end{array}$ & $\begin{array}{l}-0.477^{* *} \\
(0.044)\end{array}$ & $\begin{array}{l}-0.098 \\
(0.077)\end{array}$ & $\begin{array}{l}-0.918^{* *} \\
(0.107)\end{array}$ & $\begin{array}{l}-0.783^{* *} \\
(0.124)\end{array}$ & $\begin{array}{l}-1.677^{* *} \\
(0.344)\end{array}$ \\
\hline $\begin{array}{l}\text { High income in urban } \\
\text { region }\end{array}$ & $\begin{array}{l}0.497^{* *} \\
(0.089)\end{array}$ & $0.212^{*}(0.109)$ & $\begin{array}{l}-0.151 \\
(0.082)\end{array}$ & $\begin{array}{l}-0.522^{* *} \\
(0.075)\end{array}$ & $\begin{array}{l}-0.227^{*} \\
(0.106)\end{array}$ & $\begin{array}{l}-1.046^{* *} \\
(0.129)\end{array}$ & $\begin{array}{l}-0.123 \\
(0.142)\end{array}$ & $-1.33^{*}(0.535)$ \\
\hline $\begin{array}{l}\text { Own production of } \\
\text { millets }\end{array}$ & $\begin{array}{l}203.139^{* *} \\
(0)\end{array}$ & $0.329^{* *}(0.077)$ & $\begin{array}{l}9.159^{* *} \\
(0.111)\end{array}$ & $0.299^{* *}(0.039)$ & $\begin{array}{c}125.164^{* *} \\
(0.00)\end{array}$ & $0.489^{* *}(0.102)$ & $\begin{array}{l}13.795^{* *} \\
(1.068)\end{array}$ & $-0.051(0.188)$ \\
\hline Constant & $\begin{array}{l}-0.575^{* *} \\
(0.167)\end{array}$ & $4.244^{* *}(0.196)$ & $\begin{array}{l}-2.82^{* *} \\
(0.151)\end{array}$ & $5.198^{* *}(0.16)$ & $\begin{array}{l}-2.868^{* *} \\
(0.241)\end{array}$ & $3.36^{* *}(0.364)$ & $\begin{array}{l}-0.523 \\
(0.317)\end{array}$ & $4.692^{* *}(0.601)$ \\
\hline Rho $(\rho)$ & $\begin{array}{l}-0.058 \\
(0.053)\end{array}$ & & $\begin{array}{c}0.036 \\
(0.034)\end{array}$ & & $\begin{array}{l}0.162^{* *} \\
(0.064)\end{array}$ & & $\begin{array}{l}-0.281^{* *} \\
(0.083)\end{array}$ & \\
\hline Sigma $(\sigma)$ & $\begin{array}{l}0.791^{* *} \\
(0.014)\end{array}$ & & $\begin{array}{l}0.678^{* *} \\
(0.01)\end{array}$ & & $\begin{array}{l}0.85^{* *} \\
(0.018)\end{array}$ & & $\begin{array}{l}0.954^{* *} \\
(0.033)\end{array}$ & \\
\hline Lambda $(\lambda)$ & $\begin{array}{l}-0.046 \\
(0.042)\end{array}$ & & $\begin{array}{c}0.025 \\
(0.023)\end{array}$ & & $\begin{array}{l}0.138^{* *} \\
(0.056)\end{array}$ & & $\begin{array}{l}-0.268^{* *} \\
(0.083)\end{array}$ & \\
\hline $\begin{array}{l}\text { Wald test of independent } \\
\text { of equations }(\mathrm{rho}=0) \mathrm{chi}^{2}\end{array}$ & 1.19 & & 1.14 & & $6.2^{*}$ & & $10.27^{* *}$ & \\
\hline
\end{tabular}

Note: Figures in parentheses indicate standard errors; Double star $\left(^{* *}\right)$ indicates significant at one percent level and single star $\left({ }^{*}\right)$ indicates significant at five percent level. 